\title{
An Exploratory Study of the Participation in the Sharing Economy: What are the Influencing Variables?
}

\author{
Stephen Choi \\ California State University Fresno \\ Craig School of Business \\ Dept. of Information Systems \& Decision Sciences \\ choi@csufresno.edu
}

\author{
Sang Hyun Kim \\ Kyungpook National University \\ School of Business Administration \\ Daegu, South Korea \\ ksh@knu.ac.kr
}

\begin{abstract}
The following is an exploratory study undertaken to identify and validate the variables that affect an individual's decision to participate in the sharing economy. Six variables are tested; five as independent variables and one as a moderator variable. The five are self-technological aptness, self-norm, attitude toward the sharing economy, desire to access a bigger market, and attitude toward environmental friendliness, while the moderator variable is economic benefit. Regarding data: 1000 promiscuously recruited individuals were asked and 479 individuals completed the survey out of which 466 individuals' responses are used for the data analysis. The selfdetermination theory provides the basis for the theoretical framework and hypothesis development. The result revealed that all variables showed a statistically significant relationship, except for the selftechnologically aptness variable. Moreover, the moderating economic benefit variable exhibited a significant moderation effect on all the variables except in the case of self-technological aptness. Ultimately, this study provides a deeper understanding of those variables and their effect on the participants. Additionally, it presents opportunities for further research in this area. A full and complete report is expected later.
\end{abstract}

\section{Introduction}

The sharing economy (also known as the collaborative economy and collaborative consumption [4], [19]) is an emerging business model that resembles online peer-to-peer transaction platforms. The major difference is that instead of the traditional single vendor engaging with multiple customers, multiple customers or participants interact with multiple other participants. Some well-known examples within this economy include ride-sharing businesses like Uber and Lyft, lodging-sharing enterprises like Airbnb, and shared workspace providers like 'WeWork.' Among the many sharing economy novelties, one that stands out the most is co-ownership [20]. Essentially, in order to have a successful sharing economy market, there must be a stream of participating individuals coowning a product or sharing a service. The sharing economy continues to provide a wide variety of products and services, and as a result, its popularity is growing [22]. According to a report, $72 \%$ of American adults have used at least one of the eleven different shared or online demand services that are provided in the report [3]. The total value of the sharing economy market is expected to reach $\$ 40.2$ billion in 2022, up from $\$ 18.6$ billion in 2017 [15] and in the year 2025, it is projected to reach around $\$ 335$ billion [29].

Despite this startling growth, there are some concerns: safety [36], vandalism [31], and privacy [37]. These incidents mostly deal with human behaviors, which can be challenging to control through the sharing economy mechanisms or protocols that currently exist. Consequently, a report reveals that $72 \%$ of consumers who have experienced the sharing economy agree that they feel that the sharing economy experience is not consistent, and $69 \%$ of them agree that they will not trust a sharing economy vendor unless someone they trust recommends them [9]. However, despite the issues and concerns, the negative headlines and serious debates they generate, and the uneasiness found among the consumers, the sharing economy markets continue to grow. Given both the ever-increasing scale and value of the sharing economy, and the challenges it faces, it is more than a little surprising that the research community has not kept pace in understanding and interpreting the sharing economy phenomenon - therefore a research gap exists. A paucity of sharing economy studies [19], [14], 
[11], [6], [30] indicates that this research inquiry is just beginning in our IS community.

Given these circumstances, this study delves into the quandary with the questions of 'what' and 'why' regarding the sharing economy: What variables are influencing those individuals participate in the sharing economy? And why do they do so? These need to be investigated and validated. Furthermore, an examination needs to be made into the interaction effects among the variables.

This study aims to reach out to as many sharing economy experienced individuals as possible in order to not only secure a large data set size, but also to receive information regarding a variety of sharing economy platforms and products. Besides the popular ride sharing service (e.g. Uber or Lyft) and lodging services (e.g. Airbnb), many other sharing economy products and services across different industries and business sectors need to be looked at it. An added benefit of this approach is that it will also act positively on the generalization of the results.

In corollary, this study's theoretical contribution will be to unearth the participant's attributes and motives for participating in the sharing economy. Regarding the practical contribution of this study, the results may serve those sharing economy vendors and practitioners who are interested in what and why people choose to participate in the sharing economy market. This insightful information may provide ideas and opportunities to develop new products or improve existing products and services.

\section{Theoretical Background}

\subsection{Self-Determination Theory}

Currently, within the sharing economy domain there is no theory that stands above other theories. With that being said, for the scope of our study, selfdetermination theory provides a sound theoretical framework. Self-determination theory (SDT) focuses on the causes of an individual's motivation to act. In other words, it attempts to construe why an individual commits to an act. Ryan and Deci [32] defines the theory as "an approach to human motivation and personality that uses traditional empirical methods while employing an organismic metatheory that highlights the importance of humans' evolved inner resources for personality development and behavioral self-regulation" (page 68). In order for a person to act on the motivation, three conditions are identified as necessary: autonomy, competence, and relatedness. These conditions operationalize the motivation. The details and examples of each condition are explained in in the following hypothesis section.

Furthermore, SDT largely points to two categories of motivation: intrinsic and extrinsic. Intrinsic motivation explains the individual's biological or natural desire to please his or herself. This motivation relates not only to fulfilling the basic needs of an individual, but it also encompasses motivation stemming from societal desires such as rewards, controls, and interests. The fact is that human beings always strive to better themselves in nearly all circumstances and wants to reach the most optimal environment. Extrinsic motivation, on the other hand, focuses on the individual's particular desire relating to a given context where the outcome behavior is advantageous to the individual himself. The scope is broader than in the case of intrinsic motivation, since many more related external factors are considered.

We now have the SDT three conditions (autonomy, competence, and relatedness) as well as the two SDT categories of motivation (intrinsic and extrinsic). In the following section below, we use the SDT's three conditions and two categories of motivation in order to construe each variable's presence in the theoretical model.

\subsection{Hypothesis Development}

\section{Self-technological aptness}

This is interpreted as personal innovativeness in information technology (PIIT) [1]. When seen through the SDT lens, this is an intrinsic motivation. When joined with the concept of innovation diffusion, it speaks of the degree to which an individual manipulates a technology to their advantage [26]. It is categorized into two branches: global innovativeness (a trait that a person exhibits generally, regardless of the context) and domain-specific innovativeness (innovativeness that is highly sensitive to context). We apply PIIT in order to study sharing economy platform access and use. Currently, there is both a general understanding about the sharing economy and a specific understanding about certain goods or services (e.g. Uber or Airbnb). As an exploratory study, we expect that a significant economic benefit will positively moderate the relationship, i.e. even an individual with a low level of self-technological aptness will attempt to use the sharing economy related technologies.

\section{H1a: An individual with a high level of self- technological aptness is likely to intend to participate in the sharing economy}




\section{H1b: Economic benefit will positively moderate the effect of self-technological aptness on behavioral intention.}

\section{Self-norm}

In terms of SDT, this falls under the concept of intrinsic motivation, with the relatedness condition being present. In this case, an individual relates their self-expectations and personal values to the sharing economy's attributes and goals. For example, if an individual is an environmental activist then they are more likely to have positive relationship with the sharing economy. Similarly, if the individual is cost conscious then a positive relationship will take place with the economic benefit.

\section{H2a: An individual with a high level of self- norm is likely to intend to participate in the sharing economy \\ H2b: Economic benefit will positively moderate the effect of self-norm on behavioral intention.}

\section{Attitude toward sharing economy}

As Heider [13] points out, "an attitude towards an event can alter the attitude towards the person who caused the event, and, if the attitudes towards a person and an event are similar, the event is easily ascribed to the person" (pg. 107). Thus, attitude is the first to be evaluated in the determination of an individual's intention and behavior [2].

Among consumers, the positive response and attitude towards the sharing economy is noticeably growing as people become more familiar with the sharing concept [28], [20], [3], [15].

This positive attitude towards the sharing economy partly results from many of this economy's key features aligning with widely held virtues such as environmental friendliness, resource conservation, and sharing with others.

Translated through the SDT framework, this can be understood as an extrinsic motivation with relatedness condition present. The growing positive attitude toward sharing economy certainly increases the chance of participation. In other words, the attitude relates to the participation.

A positive attitude and more participation consequently create a positive link between the attitude and the economic benefits.
H3a: An individual with a positive attitude toward the sharing economy is likely to intend to participate in the sharing economy

\section{H3b: Economic benefit will positively moderate the effect of the attitude toward the sharing economy on behavioral intention.}

\section{Desire to access a bigger market}

Access to a bigger market means an individual may choose from a list of goods or services that is longer and broader than that offered by a traditional vendor. For example, an individual may choose an overnight stay from Airbnb's over 6 million unique places in nearly 100,000 cities and 191 countries (www.airbnb.com). This is bigger inventory than that of any other overnight stay accommodation vendor. This wider selection attracts those who seek a good or service at places where an established vendor may not be able to provide similar accommodations.

In terms of the SDT, this is considered an extrinsic motivation. The autonomy and competence conditions are present as well. As relating to economic benefit, the result of the sharing economy's ability to offer different price ranges depending on the quality of the good or service will attract a variety of consumers, from those seeking a bargain to those interested in luxury. Thus, the economic benefit will positively influence the relationship between access to a bigger market and the consumer's intentions towards use.

\section{H4a: An individual who desires to access a bigger market is likely to intend to participate in the sharing economy}

\section{H4b: Economic benefit will positively moderate the effect of the desire to access a bigger market on behavioral intention.}

\section{Environmental friendliness}

Environment-friendliness (or eco-friendliness) and the movement toward conserving energy and resources has emerged as not only an alternative, but also a necessity in some places in our world [35]. The sharing economy is closely aligned with this growing interest. The sharing economy yields no environmental waste in many of its transactions, thereby preserving the environment and conserving energy. Additionally, the sharing economy allows existing resources to be utilized more efficiently, therefore lessening the need to produce additional homes, vehicles, and so on. 
Viewed through the SDT lens, this is an extrinsic motivation, while the autonomy and competence conditions are also present. It is important to note that there is less autonomy here as environmental friendliness is not only rapidly becoming an industry standard, but also a key demand of governments and the public. Owning less and sharing more will certainly positively moderate the relationship.

\section{H5a: An individual with a high level of environmental friendliness is likely to intend to participate in the sharing economy \\ H5b: Economic benefit will positively moderate the effect of environmental friendliness on behavioral intention.}

\section{Economic benefit}

Probably the most common reason why people participate in the sharing economy is cost. The economic benefit is featured as a major driver of sharing economy [16], [17], [12]. Sharing or borrowing a product, for instance, in many cases drastically lowers the economic burden compared to purchasing or owning. This cost difference is so tempting that it may overcome other issues. Viewed through the SDT lens, this is best understood as an extrinsic motivation where an individual is moved by the unusual economic advantage. The conditions present are autonomy and relatedness. An individual's personal financial situation may compel them to consider participating in the sharing economy. Consequently, the accompanying economic benefit variable may significantly moderate the other variables.

\section{Participation}

While not the primary theory in this study, Planned Behavior theory [2] does provide a theoretical support to SDT under the scope of this study. The six variables in this study appropriately associate with the attitudes toward the behavior, subjective norms with respect to the behavior, and perceived control over the behavior of the planned behavior theory [9]. Given the wellestablished empirical effectiveness of the planned behavior theory, the intention to participate in the sharing economy will lead to actual participation.

\section{H6: The intention to participate in the sharing economic does lead to actual participation.}

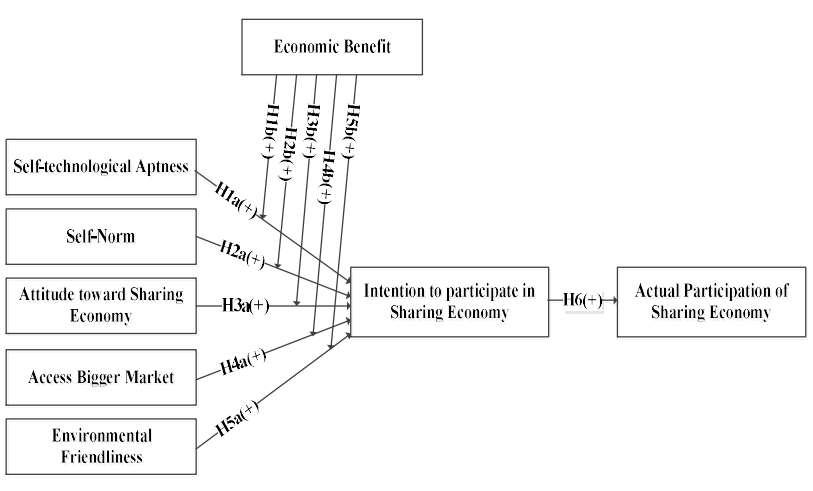

Figure 1. Research Model

\section{Method}

\subsection{Instrument development}

In order to validate the variables and research model [33], [34], a field survey instrument had to be developed [27], [8]. Based on the variables or constructs from the hypotheses, relevant questionnaire items had to be formulated according to the context and scope of the study. Consequently, a list of published sharing economy articles were evaluated along with relevant literature. Furthermore, for the purposes of objectivity and in order to develop a wider pool of questionnaire items, a group of information systems faculty and graduate students were consulted. Only the suggested questionnaire items that received a majority vote were kept for the further processing.

Each item is measured on a 7-point, Likert-type scale, ranging from 1 (strongly disagree) to 7 (strongly agree). Additionally, before running a few rounds of a pilot study, the instrument was reviewed by business school professors and a few minor changes were implemented based on their recommendations.

Afterwards, pilot runs were administered using university students. University students were selected because their age group is likely to patronize the sharing economy platforms and vendors. The pilot run's purpose was to fine tune the instrument and find any issues with wording, content, format, and procedures. A total of 46 students participated in the pilot run. We discarded two incomplete responses, so thereby 44 responses were used to analyze the pilot study. The pilot participants' result provided valuable insights and written comments that assisted in finetuning the instrument. Moreover, their comments provided colorful personal accounts. 
Factor analysis and Cronbach's alpha are used for the instrument validation [34], [27], [24]. Only those constructs with a Cronbach's alpha value 0.70 or higher were kept and others were dropped [21]. Based on the pilot result, a few changes were made to the instrument in terms of wording and sentence structures. Additionally, the two extra items were added in order to keep the participants honest with their responses and guard against any careless responses. The final instrument had six constructs and each carried three items.

\subsection{Participants and Data Collection}

Many of the published empirical studies use college students as study participants. This is largely because there are restrictions, limited resources, and a lack of viable access to a greater diversified general population. However, for a study results generalizability, a more diversified general population is highly recommended. Although the sharing economy is closely associated with younger age groups, there is a growing interest among other age groups as well. A recent report finds that "Americans ages 35-44 are nearly twice as likely as those ages 1824 to have used home-sharing services ( $16 \%$ vs. 9\%), and the median age of home-sharing users in the United States is 42." [22]. Given this compelling trend, the importance of the study's generalizability is more essential.

In light of the importance of generalizability, we carefully planned and administered the survey instrument to a population that more reflects the public. In order to ensure that our respondents covered a broad age range, a number of graduate students and some paid-workers were identified as a survey data collection resource. The data collection was undertaken during the 2017-2018 school year.

In order to target where we would use our resources to do the survey data collection, we identified locations where large crowds of people are frequently present, such as bus terminals, an university library lobby, train stations, university campuses, downtown business districts, and shopping malls. We targeted the busy hours of these places. For each respondent, we would politely ask the person to participate in a short survey, provide a brief explanation of the survey's background, and explain the study's purpose. We conducted this for a several months.

The respondents were promiscuously recruited regardless of their gender or age. We targeted 1000 people, 479 of whom completed the survey. Of the completed survey, 13 were discarded due to their incomplete responses. At the end, 466 final survey responses were saved for the data analysis. All responses were entered into a Microsoft Excel sheet and organized according to the constructs, corresponding items, and the background information. Table 1 shows the demographic of the respondents.

Table 1. Participants' Demographic

\begin{tabular}{|l|l|l|l|}
\hline \multicolumn{2}{|l|}{ Demographic categories } & $\mathrm{n}$ & $\%$ \\
\hline \multirow{4}{*}{ Age } & $\geq 19$ & 21 & $4.5 \%$ \\
\cline { 2 - 4 } & $20-29$ & 197 & $42.3 \%$ \\
\cline { 2 - 4 } & $30-39$ & 116 & $24.9 \%$ \\
\cline { 2 - 4 } & $40-49$ & 76 & $16.3 \%$ \\
\cline { 2 - 4 } & $50+$ & 56 & $12.0 \%$ \\
\hline \multirow{4}{*}{ Occupation } & Male & 297 & $63.7 \%$ \\
\cline { 2 - 4 } & Female & 169 & $36.3 \%$ \\
\hline & Student & 174 & $37.3 \%$ \\
\cline { 2 - 4 } & Office Worker & 102 & $21.9 \%$ \\
\cline { 2 - 4 } & Technician & 47 & $10.1 \%$ \\
\cline { 2 - 4 } & Professional & 56 & $12.0 \%$ \\
\cline { 2 - 4 } & Self-Employed & 66 & $14.2 \%$ \\
\cline { 2 - 4 } & Others & 21 & $4.5 \%$ \\
\hline
\end{tabular}

\section{Data Analysis and Results}

For our statistical analyses, AMOS 22.0 is used. We first examined the measurement model to assess reliability and validity before testing the structural model. We provide the measurement and structural models assessments below.

\subsection{Measurement Model}

First, the overall fitness is examined to see if the collected dataset fits well with the measurement model. Several indices are used from the analysis outputs of confirmatory factor analysis (CFA) such as NFI, GFI, AGFI, CFI, RMSEA, and the relative chi-square $(\chi 2 / \mathrm{df})$ [5]. Table 2 below shows the results of the overall fitness along with the threshold.

The convergent and discriminant validity, and reliability of the measurement model are tested by the means of three assessments: item loading, average variance extracted (AVE), composite reliability (CR), and Cronbach's Alpha. First, the CFA test reveals that the individual items loaded on their respective latent variables well. The factor loadings ranged from 0.731 to 0.915 , demonstrating the convergent validity. Additionally, AVE and $\mathrm{CR}$ values are above the threshold 0.5 and 0.7 , respectively [7]. The reliability of the measurement model is checked by using Cronbach's Alpha of each latent variable. The threshold of alpha is 0.7 [21]. The results show that the alphas ranged from 0.757 to 0.941 , demonstrating the 
validity of the measurement model. Table 3 below describes the analysis results of the convergent validity and reliability test.

The discriminant validity of the measurement model is checked by comparing the square root of AVE with the correlation among the latent variables. To demonstrate the discriminant validity, the value of the correlation in horizontal and vertical should be smaller than the square root of AVE diagonal for each latent construct [7]. Table 4 shows the results of discriminant validity.
Table 2. Goodness of fit

\begin{tabular}{|l|l|l|}
\hline & Model & Threshold \\
\hline NFI & 0.929 & $\geq 0.9$ \\
\hline GFI & 0.936 & $\geq 0.9$ \\
\hline AGFI & 0.897 & $\geq 0.8$ \\
\hline CFI & 0.950 & $\geq 0.9$ \\
\hline RMSEA & 0.041 & $\leq 0.05$ \\
\hline$X^{2} / d f$ & 1.831 & $\geq 3.0$ \\
\hline
\end{tabular}

Table 3. Reliability and Convergent Validity Test

\begin{tabular}{|l|c|c|c|c|l|c|c|}
\hline Latent Variables & Items & Mean & Std & $\begin{array}{c}\text { Item } \\
\text { Loadings }\end{array}$ & AVE & CR & $\begin{array}{c}\text { Cronbach' } \\
\text { s Alpha }\end{array}$ \\
\hline $\begin{array}{l}\text { Self-technological } \\
\text { Aptness (ST) }\end{array}$ & 3 & $4.259-5.220$ & $0.965-1.447$ & $.845-.886$ & .759 & .904 & 0.836 \\
\hline Self-Norm (SN) & 3 & $4.620-5.170$ & $0.994-1.190$ & $.763-.892$ & .658 & .852 & 0.898 \\
\hline $\begin{array}{l}\text { Attitude toward Sharing } \\
\text { Economy (AT) }\end{array}$ & 3 & $4.802-5.009$ & $1.071-1.218$ & $.785-.897$ & .705 & .878 & 0.910 \\
\hline $\begin{array}{l}\text { Access Bigger Market } \\
\text { (BM) }\end{array}$ & 3 & $5.280-5.797$ & $1.164-1.289$ & $.764-.850$ & .634 & .838 & 0.757 \\
\hline $\begin{array}{l}\text { Environmental } \\
\text { Friendliness (EF) }\end{array}$ & 3 & $4.746-5.034$ & $1.053-1.332$ & $.801-.877$ & .704 & .877 & 0.812 \\
\hline Economic Benefit (EB) & 3 & $5.323-5.842$ & $0.997-1.205$ & $.759-.912$ & .714 & .881 & 0.859 \\
\hline $\begin{array}{l}\text { Intention to use Sharing } \\
\text { Economy (INT) }\end{array}$ & 3 & $5.250-5.435$ & $0.965-1.354$ & $.797-.831$ & .685 & .852 & 0.927 \\
\hline $\begin{array}{l}\text { Actual usage of Sharing } \\
\text { Economy (AU) }\end{array}$ & 3 & $5.099-5.731$ & $1.042-1.265$ & $.782-.859$ & .671 & .859 & 0.941 \\
\hline
\end{tabular}

Table 4. Discriminant Validity Test

\begin{tabular}{|c|c|c|c|c|c|c|c|c|}
\hline $\begin{array}{c}\text { Latent } \\
\text { Variable }\end{array}$ & ST & SN & AT & BM & EF & EB & INT & AU \\
\hline ST & $\mathbf{0 . 8 7 1}$ & & & & & & & \\
\hline SN & 0.167 & $\mathbf{0 . 8 1 1}$ & & & & & & \\
\hline AT & 0.273 & 0.211 & $\mathbf{0 . 8 4 0}$ & & & & & \\
\hline BM & 0.225 & 0.355 & 0.424 & $\mathbf{0 . 7 9 6}$ & & & & \\
\hline EF & 0.209 & 0.310 & 0.422 & 0.390 & $\mathbf{0 . 8 3 9}$ & & & \\
\hline EB & 0.189 & 0.264 & 0.360 & 0.245 & 0.371 & $\mathbf{0 . 8 4 5}$ & & \\
\hline INT & 0.247 & 0.286 & 0.397 & 0.314 & 0.231 & 0.447 & $\mathbf{0 . 8 1 1}$ & \\
\hline AU & 0.280 & 0.170 & 0.391 & 0.442 & 0.179 & 0.228 & 0.337 & $\mathbf{0 . 8 1 9}$ \\
\hline
\end{tabular}

\subsection{Structural model}

In order to demonstrate common method variance (CMV), we performed a single factor test using the Harman's single-factor analysis with all items from all constructs in order to determine whether the majority of the variance in the research model can be accounted for by one general factor [23]. Unrotated factor analysis using principal component analysis yielded six factors. The first factor explained about $31 \%$ of the variance, which certainly does not constitute a majority of the total variance, as a recent study by Malhotra et al. [18] reported $40 \%$ as not being a majority of variance. Thus, the result of Harman's single-factor 
test indicates that the CMV in this study is not likely a major issue.

We formulated the structural equation model (SEM) with AMOS 22.0 in order to test proposed hypotheses in the research model. SEM analysis not only provides the standardized coefficient $(\beta)$, but also the squared multiple correlation $\left(\mathrm{R}^{2}\right)$ of each endogenous variable. The standardized coefficient $(\beta)$ with corresponding $p$-value is the key judgment to decide whether to accept the hypotheses whereas the squared multiple correlation $\left(\mathrm{R}^{2}\right)$ is used to explain the amount of variance in each endogenous variable by exogenous variables.

The SEM analysis shows that majority of proposed hypotheses were significantly supported. However, the relationship between self-technological aptness and intention to utilize the sharing economy was not significant. Thus, H1 was rejected. This result implies that individuals who are interested in sharing economy services do not use the service due to their own interests in the newest trends and services. Among four self-intrinsic variables, attitude toward sharing economy has the highest impact on intention to use the sharing economy. Furthermore, the overall fitness of the SEM model demonstrates that the research model is a reasonable account of the structures, underlying the observed data. All indices had a value more than the threshold $(\mathrm{NFI}=0.961, \mathrm{GFI}=0.944$, AGFI $=0.920$, $\mathrm{CFI}=0.968$, $\mathrm{RMSEA}=0.025$, and $\left.\mathrm{X}^{2} / \mathrm{df}=1.997\right)$.

Regarding $\mathrm{R}^{2}$ of each endogenous variable (intention to use sharing economy), six exogenous variables (self-technological aptness, self-norm, attitude, trust, access bigger market, and environmental friendliness) explained about $65.7 \%(0.657)$ of the variance in the intention to use the sharing economy, implying that $65.7 \%$ of the information on the intention to use the sharing economy moves in the same direction as these eight exogenous variables move. In addition, the $\mathrm{R}^{2}$ of actual usage of the sharing economy was 0.200 , indicating that the intention to use the sharing economy explained approximately $20.0 \%$ of the variance in actual usage of sharing economy.

For the economic benefit moderating effect, except H1, all hypotheses are supported $(p<0.01)$. These results imply that the economic benefit significantly strengthens those relationships of supported paths. Table 5 below summarizes the hypotheses results.

Table 5. Research Model

\begin{tabular}{|l|l|c|c|c|}
\hline Hypothesis & \multicolumn{1}{|c|}{ Path } & Std. $\beta$ & t-value & Result \\
\hline $\mathrm{H} 1 \mathrm{a}$ & $\begin{array}{l}\text { Self-technological Aptness } \rightarrow \text { Intention to use Sharing } \\
\text { Economy }\end{array}$ & 0.076 & 0.805 & $\mathrm{NS}$ \\
\hline $\mathrm{H} 1 \mathrm{~b}$ & $\begin{array}{l}\text { Self-technological Aptness } \times \text { Economic Benefits } \rightarrow \\
\text { Intention to use Sharing Economy }\end{array}$ & 0.025 & 0.594 & $\mathrm{NS}$ \\
\hline $\mathrm{H} 2 \mathrm{a}$ & $\begin{array}{l}\text { Subjective Norm } \rightarrow \\
\text { Intention to use Sharing Economy }\end{array}$ & 0.271 & 4.531 & $\mathrm{~S}^{* *}$ \\
\hline $\mathrm{H} 2 \mathrm{~b}$ & $\begin{array}{l}\text { Subjective Norm } \times \text { Economic Benefits } \rightarrow \\
\text { Intention to use Sharing Economy }\end{array}$ & 0.227 & 4.536 & $\mathrm{~S}^{* *}$ \\
\hline $\mathrm{H} 3 \mathrm{a}$ & $\begin{array}{l}\text { Attitude toward Sharing Economy } \rightarrow \text { Intention to use } \\
\text { Sharing Economy }\end{array}$ & 0.329 & 5.150 & $\mathrm{~S}^{* *}$ \\
\hline $\mathrm{H} 3 \mathrm{~b}$ & $\begin{array}{l}\text { Attitude toward Sharing Economy } \times \text { Economic Benefits } \rightarrow \\
\text { Intention to use Sharing Economy }\end{array}$ & 0.283 & 4.991 & $\mathrm{~S}^{* *}$ \\
\hline $\mathrm{H} 4 \mathrm{a}$ & $\begin{array}{l}\text { Access Bigger Market } \rightarrow \text { Intention to use Sharing Economy } \\
\text { Iccess Bigger Market } \times \text { Economic Benefits } \rightarrow\end{array}$ & 0.236 & 3.885 & $\mathrm{~S}^{* *}$ \\
\hline $\mathrm{H} 4 \mathrm{~b}$ & $\begin{array}{l}\text { Intention to use Sharing Economy } \\
\text { Intention to use Sharing Economy }\end{array}$ & 0.284 & 4.118 & $\mathrm{~S}^{* *}$ \\
\hline $\mathrm{H} 5 \mathrm{a}$ & $\begin{array}{l}\text { Environmental Friendliness } \times \text { Economic Benefits } \rightarrow \\
\text { Intention to use Sharing Economy }\end{array}$ & 0.225 & 3.609 & $\mathrm{~S}^{* *}$ \\
\hline $\mathrm{H} 5 \mathrm{~b}$ & $\begin{array}{l}\text { Intention to participate } \rightarrow \text { Actual participation } \\
\mathrm{H} 6\end{array}$ & 0.447 & 6.852 & $\mathrm{~S}^{* *}$ \\
\hline
\end{tabular}

$\mathrm{NS}=$ not supported, $\mathrm{S}^{* *}=$ significantly supported $\mathrm{p}<0.01$ 


\section{Discussion}

H1a's self-technological aptness and the economic benefit moderation effect in H1b turned out to be nonsignificant. Self-technological aptness, which is analogous to personal innovation in IT, speaks to an individual's inherent technology inclination. An explanation can be found in the fact that the userfriendly features of most sharing economy platforms lower the technological barrier. In other words, an individual does not have to be technologically savvy in order to effectively use most sharing economy platforms and services. Along with this, the economic benefit moderation effect is negated.

The H2a's self-norm $(\beta=.271, p<.01)$ and the H2b's economic benefit moderation $(\beta=.227, \mathrm{p}<.01)$ exhibited significant results. Self-norm, closely related to social influences such as peer pressure and group expectation, has been validated under the technology acceptance rubric. One of the survey items asks, "Do many of your close friends and family members patronage sharing economy sites?" and close to $80 \%$ of respondents answered yes. Thus, social influence has an impact on supporting the hypothesis. The significant economic benefit moderation effect also coincides with the selfnorm and its value. If an individual's norm is cost conscious then the economic benefit makes a significant impact on decision-making.

The H3a's attitude toward sharing economy $(\beta=.329, \quad p<.01)$ and the H3b's economic benefit moderation $(\beta=.283, \mathrm{p}<.01)$ also proved significant in the results. The positive attitude toward the sharing economy clearly leads an individual to intend to participate. The positive attitude manifests from positive expectations, which themselves relate to the sharing economy's attributes. Adding to this is the economic benefit the sharing economy offers: the cheaper cost, wider selection and greater availability of goods and services certainly eases decision-making.

The H4a's access to a bigger market $(\beta=.236$, $\mathrm{p}<.01)$ and H4b's economic benefit moderation $(\beta=.283, p<.01)$ are reported as significant in the results. Not only does a bigger market offer a wider selection in products and services, but it also offers an individual a rare opportunity to consume a pricey product or service at a reasonable cost [25], [10]. In a traditional business market, this would usually not be possible, but the larger sharing economy systematically allows these opportunities for a reasonable cost to an ordinary individual.

The H5a's environmental friendliness $(\beta=.225$, $\mathrm{p}<.01)$ and H5b's economic benefit moderation $(\beta=.313, p<.01)$ were also proved to be significant in the results. In our current time, environmental friendliness is a highly sought-after quality. Given the increasing interest in environmental friendly goods and services (e.g. electric cars and solar powered home heating and cooling), the sharing economy's environmental friendliness strengthens its overall appeal. Furthermore, the sharing or co-owning of a product drastically reduces the creation of environmental hazardous wastes, which are hard to dispose.

Finally, H6, the relationship between the individual's intention to participate in the sharing economy and the actual participation was significant with the coefficient of 0.447 ( $\mathrm{t}$-value $=6.852)$. This confirms the strong and significant relationship between the intentions to participate that reflects the positive perception of sharing economy, and the actual participation.

\section{Conclusion}

This is a preliminary report that highlights the major findings resulting from the study of the variables that influence why people participate in sharing economy markets.

Among the significant components of this study is the data size (1000 people were initially asked and 466 data points were secured), and the generalizability of dataset (the study examines not only the usage of popular services like Uber and Airbnb, but also many other diverse sharing economy products and services).

Concerning the theoretical contribution, the following variables are found to be significant in influencing an individual's intent to participate: selfnorm, attitude toward sharing economy, access to a bigger market, and environmental friendliness. Additionally, the moderating effect of the economic benefit variable proved significant. Conversely, the self-technological aptness variable is found to be nonsignificant as many of the sharing economy platforms are user-friendly enough even for novice users.

A full detailed report is expected in the near future. This report will feature deeper data analysis and an insightful discussion of the results.

Overall, given the expected robust growth of sharing economy markets, more studies using the IS perspective are needed in order to better understand its continual growth and impact.

\section{References}

[1] R. Agarwal, and Prasad, J. "A Conceptual and Operational Definition of Personal Innovativeness in the Domain of Information Technology," Information Systems Research, 9(2), 1998, pp. 204-215. 
[2] I. Ajzen, "The Theory of Planned Behavior," Organizational Behavior and Human Decision Processes, 50, 1991, pp.179-211.

[3] M. Anderson. "Americans and the new digital economy: 8 key findings," printed May 19, 2019, retrieved on June 14, 2019. https://www.pewresearch.org/facttank/2016/05/19/digital-economy-key-facts/

[4] M. Avital, M. Andersson, J. Nickerson, A. Sundararajan, V. Alstyne. "The collaborative economy: a disruptive innovation or much ado about nothing?." Proceedings of the 35th International Conference on Information Systems; ICIS 2014. Association for Information Systems. AIS Electronic Library, Auuckland New Zealand, 2014.

[5] P. Bentler, "Comparative fit indexes in structural models," Psychological Bulletin, 107, 1990, pp. 238246.

[6] T. Berger, C. Chen, and C.B. Frey, "Drivers of disruption? Estimating the Uber effect." European Economic Review 110 (2018): 197-210.

[7] W. Chin. The partial least squares approach for structural equation modeling. In G.A. Marcoulides (Ed.) Modern methods for business research (pp. 295-336). Hillsdale, NJ: Lawrence Erlbaum. 1998.

[8] DeVellis, R.F., Scale Development: Theory and Applications, 2nd ed., Example Product Manufacturer, 2003.

[9] PricewaterhouseCoppers, The Sharing Economy: Consumer Intelligence Series, Printed Feb 19, 2019. https://www.eurofound.europa.eu/data/platformeconomy/records/the-sharing-economy-consumerintelligence-series

[10] A. Gibbs. 2015. The sharing economy gets a taste for luxury, CNBC.com, published sept $18^{\text {th }} 2015$. https://www.cnbc.com/2015/09/18/sharing-economygetting-a-taste-for-luxury.html

[11] B.N. Greenwood and Wattal, S., "Show Me the Way to Go Home: An Empirical Investigation of Ride-Sharing and Alcohol Related Motor Vehicle Fatalities," MIS quarterly, 41(1), 2017, pp.163-187.

[12] J. Hamari, M. Sjöklint, and A. Ukkonen, "The sharing economy: Why people participate in collaborative consumption," Journal of the association for information science and technology, 67(9), 2016, pp. 2047-2059.

[13] F. Heider. "Attitudes and Cognitive Organization," The Journal of Psychology, 21, 1946, pp.107-112.

[14] B. Jiang and L.B. Tian, "Collaborative Consumption: Strategic and Economic Implications of Product
Sharing," Management Science, 64(3), 2016, pp. 9831476

[15] Juniper research, "Sharing economy revenues to double by 2022 , Reaching over $\$ 40$ billion," Data retrieved May 24, 2019. https://www.juniperresearch.com/press/pressreleases/sharing-economy-revenues-to-double-by-2022

[16] J. Kim, Y. Yoon, and H. Zo, "Why People Participate in the Sharing Economy: A Social Exchange Perspective," Pacific Asia Conference Information Systems, Singapore, 2015.

[17] M. Koohikamali, A. Sarkar and J.B. Pick, "Motivations to participate in sharing economy: How location matters?" Americas Conference of Information Systems, Boston, 2017

[18] N. K. Malhotra, S. S. Kim, and A. Patil, "Common method variance in IS research: A comparison of alternative approaches and a reanalysis of past research," Management Science, 52(12), 2006, pp. $1865-1883$

[19] M. Möhlmann, "Collaborative consumption: determinants of satisfaction and the likelihood of using a sharing economy option again," Journal of Consumer Behaviour, 14(3), 2015, pp.193-207.

[20] P. Nelson, "Sharing economy accelerates as attitudes towards possessions change," 2015. https://www.itworld.com/article/2913799/sharingeconomy-accelerates-as-attitudes-towards-possessionschange.html

[21] Nunnally, J. Psychometric Theory (2nd ed.). McGrawHill, New York, NY. 1978

[22] Pew Internet, 2016. Shared, Collaborative and On Demand: The New Digital Economy, https://www.pewresearch.org/internet/2016/05/19/thenew-digital-economy/

[23] P.M. Podsakoff, S.B. MacKenzie, J-Y, Lee, and N.P. Podsakoff, "Common method biases in behavioral research: A critical review of the literature and recommended remedies," Journal of Applied Psychology, 88(5), 879-903. 2003

[24] Cohen, R. J., and E. M. Swerdlik. Psychological testing and assesment. New York: McGraw-Hill Book Co, 2002.

[25] F.M. Rivera, 2018. Lifestyles for rent - luxury brands courtesy of the sharing economy. EuropeanCEO, published on $\quad$ Sept $\quad 4^{\text {th }} \quad 2018$, 
https://www.europeanceo.com/lifestyle/lifestyle-forrent-luxury-brands-courtesy-of-the-sharing-economy/

[26] Rogers, E. M. Diffusion of Innovations, 5th ed., New York, NY: the Free Press, 2003.

[27] Rosenthal, R., and R.L. Rosnow, Essentials of Behavioral Research: methods and data analysis. 2nd ed., McGraw-Hill, 1991.

[28] A. Smith, "Sharing and on-demand services attract a small but active group of 'super users"', June 30, 2016. https://www.pewresearch.org/facttank/2016/06/30/sharing-and-on-demand-servicesattract-a-small-but-active-group-of-super-users/

[29] S. Tabcum Jr. "The Sharing Economy Is Still Growing, And Businesses Should Take Note," 2019, Date retrieved May 23, 2019, https://www.forbes.com/sites/forbeslacouncil/2019/03/0 4/the-sharing-economy-is-still-growing-and-businessesshould-take-note/\#21edeb464c33

[30] T.A. Weber. "Intermediation in a sharing economy: insurance, moral hazard, and rent extraction," Journal of Management Information Systems, 31(3), pp.35-71. 2014

[31] Lim, D. 2018. \$5.3 million home in San Francisco wrecked after Airbnb rental, ABC News, Printed on Sept 7th 2018, https://abc7news.com/airbnb-rentalhome-trashed-drug-needles/4174778/

[32] R.M. Ryan and E.L. Deci, 2000. Self-Determination Theory and the Facilitation of Intrinsic Motivation, Social Development, and Well-Being, American

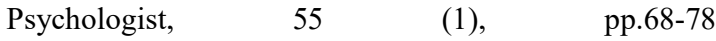

[33] M. Boudreau, D. Gefen, and D. W. Straub. "Validation in information systems research: A state-of-the-art assessment." MIS quarterly (2001): 1-16.

[34] D.W. Straub, 1989. Validating instruments in MIS research. MIS Quarterly, 13(2), pp. 147-169.

[35] BBC News. 2020. Petrol and diesel car sales ban brought forward to 2035. Published Feb $4^{\text {th }}, 2020$. https://www.bbc.com/news/science-environment51366123

[36] Salam, M. 2019. What's my name stresses safety for Uber riders, The New York Times, Printed on April 16, 2019. https://www.nytimes.com/2019/04/16/business/ubersafety.html

[37] Mettler, K. 2019. They were settling into their Airbnb then they found a hidden camera, Washington Post, Printed on April 6th, 2019. https:/www.washingtonpost.com/technology/2019/04/ 06/they-were-settling-into-their-airbnb-then-theyfound-hidden-camera/ 